ITC 2/46

Journal of Information Technology and Control

Vol. 46 / No. 2/ 2017

pp. 246-259

DOI 10.5755/j01.itc.46.2.13972 1

(c) Kaunas University of Technology
Robust Adaptive Control for Fractional-Order Financial Chaotic Systems with System Uncertainties and External Disturbances

Received 2016/01/14

\title{
Robust Adaptive Control for Fractional-Order Financial Chaotic Systems with System Uncertainties and External Disturbances
}

\section{Heng Liu}

Department of Applied Mathematics, Huainan Normal University, Huainan 232038, China College of Mathematics and Information Science, Shaanxi Normal University, Xi'an 710119, China

\section{Shenggang Li}

College of Mathematics and Information Science, Shaanxi Normal University, Xi'an 710119, China e-mail: shengganglinew@126.com

\section{Guanjun Lia, Hongxing Wang}

Department of Applied Mathematics, Huainan Normal University, Huainan 232038, China

Corresponding author: shengganglinew@126.com

In this paper, robust adaptive control for uncertain fractional-order financial chaotic systems with bounded unknown external disturbances is studied. By utilizing the fractional-order extension of the classical Lyapunov stability methods, an adaptive controller is presented for controlling the fractional-order financial chaotic system. Quadratic Lyapunov functions are employed in the stability analysis, and fractional-order adaptation laws are designed to update controller parameters online. The proposed controller can ensure that the system states converge to the origin asymptotically and all signals in the closed-loop system remain bounded. Finally, simulation results are presented to confirm our theoretical results.

KEYWORDS: Robust control, fractional-order financial system, fractional-order chaotic system, fractional-order adaptation law. 


\section{Introduction}

In the last two decades, fractional-order systems have received a significant amount physicists' and engineers' interest due to their attractive properties and potential applications [6, 12, 19, 23, 25, 29, 30, 37, 39]. Compared with classical integer-order systems, the fractional-order derivation has two advantages. First, the traditional integer-order derivative describes a certain attribute or variation at a particular time for a physical process, yet the fractional-order's is concerned throughout the whole time domain. Second, the traditional integer-order derivative indicates the local properties, for example, a certain position, for a physical process, while the fractional-order derivative is related to the whole space. Taking the above facts into account, the fractional calculus plays a very important role in the modeling and tackling of many phenomena and actual systems in various fields, such as quantum mechanics, molecular spectroscopy, stochastic diffusion, control theory, and viscoelastic dynamics $[4,11,16,20,21,22,24,45,49]$. Therefore, research on theory and applications of fractional-order systems is becoming more and more popular.

Recently, research on the complex dynamics of financial systems has also become a very prominent domain in both micro and macroeconomics [43]. Researchers have attempted to elaborate the primary properties of economic data with the help of the dynamical behaviors exhibited in the financial systems. Some continuous nonlinear system models have been established to investigate the complex economic dynamics, for example, the forced van der Pol model [38], the Goodwin's accelerate model [26], the IS-LM model [15]. In fact, it is feasible for nonlinear systems to exhibit chaotic or periodic behaviors. However, if chaotic behaviors exist in economic systems, then the systems will have inherent indefiniteness which makes it hard to provide a reasonable or effective economic prediction. Thus, it is indispensable to investigate the chaotic behaviors in financial and economical systems. Since chaotic behaviors in financial and economical systems were firstly investigated in 1985 , great impact had been put on the prominent economics. Many interesting results on integer-order financial chaotic systems were given, for example, sliding mode control and passive control methods were employed to synchronize two chaotic financial systems with different initial conditions in [18]; control of hyperchaotic finance systems was presented in [48] and [42]; chaotic dynamic behavior analysis for a class of financial risk systems was studied in [50]; control of chaotic financial systems with input time-delay by means of $\mathrm{H}_{\infty}$ control was presented in [51]; in [40], a novel 3-D nonlinear financial chaotic system was introduced and its complex dynamic behavior was investigated, etc.

Up to now, controlling and synchronizing chaos in fractional-order financial systems has also been investigated, for example, in $[1,10,13,14,27,32,41$, $43,47,46]$. In [14], a sliding mode controller was designed to synchronize fractional-order financial systems in master-slave structure. In [41], a necessary condition was given to show the existence of 1-scroll, 2-scroll even multi-scroll chaotic attractors in fractional-order financial systems. Active control method was used in [27, 47]. An active controller with multiple conflicting objectives was constructed in [32]. It should be highlighted that a key assumption in the above literatures is that the model of the financial systems should be known. However, most of real world systems are subjected to system uncertainties and external disturbances, especially in financial systems $[7,8,27,33,34,36$, 44]. On the other hand, in financial systems, system uncertainties do exist because of limited sizes of weather variables, political events, and other human factors. The existence of systems uncertainties and external disturbances could decrease the control performance, or even lead to instability of the system [35]. It is meaningful to consider the control of financial systems with system uncertainties and external disturbances. Thanks to the works of Li et al. [20], the Lyapunov direct method (also called the Lyapunov second method) has been extended to fractional-order nonlinear systems. In this paper, a robust adaptive controller is proposed to solve the control problem of fractional-order financial chaotic systems with both system uncertainties and bounded external disturbances. The fractional-order Lyapunov approach is used to analyze the stability of the system. Specifically, the main contributions of this study include:

- A robust adaptive controller is derided for fractional-order financial chaotic systems with unknown system dynamics and external disturbances; 
Fractional-order adaptations laws are constructed to eliminate the estimation errors, and a fractional Lyapunov stability criterion as well as quadratic Lyapunov functions are used in the stability analysis.

The remainder of this paper is organized as follows: Section 2 lists mathematical model of the fractional-order financial systems and some basic results on fractional calculus. In Section 3, an adaptive robust controller is designed and stability analysis of the closed-loop system is discussed. Simulation studies are included in Section 4. Finally, Section 5 concludes this work.

\section{Problem Statement and Preliminaries}

\section{Preliminaries}

The fractional order integrodifferential operator is the extended concept of the integer-order integrodifferential operator. The commonly used definitions in literatures are Grunwald-Letnikov, Riemann-Liouville, and Caputo definitions. Because the Caputo derivative takes on the same form as integer-order differential on the initial conditions, which have well-understood physical meanings and have more applications in engineering, we will use this definition. The lower limit of the fractional calculus is set as 0 in this paper. The fractional-order integral with order $\alpha$ can be expressed as

$$
{ }_{0} D_{t}^{-\alpha} f(t)=\frac{1}{\Gamma(\alpha)} \int_{0}^{t}(t-\tau)^{\alpha-1} f(\tau) d \tau .
$$

where $\Gamma(\cdot)$ represents the Euler's function.

The Caputo fractional derivative is defined as follows:

$$
{ }_{0}^{C} D_{t}^{\alpha} f(t)=\frac{1}{\Gamma(n-\alpha)} \int_{0}^{t}(t-\tau)^{n-\alpha-1} f^{(n)}(\tau) d \tau,
$$

where $\alpha$ is the fractional order, and $n$ is an integer satisfying $n-1 \leq \alpha<n$.

In nonlinear systems, Lyapunov direct method (also called the Lyapunov second method) provides a way to analyze the stability of a system without explicitly solving the differential equations. Although the Lyapunov stability theory for integer-order systems was proposed in 1892 and it has been studied and modified by lots of expert researchers, the Lyapunov stability theory for fractional order systems has been developed until recently [20].

The following lemmas and definition will be used.

Lemma 1. [20] Let $x=0$ be an equilibrium of the fractional-order nonlinear system:

$$
{ }_{0}^{C} D_{t}^{\alpha} x(t)=f(x) .
$$

Suppose there exists a Lyapunov function $V(t, x(t))$ and class- $k$ functions $g_{i}, i=1,2,3$ such that:

$$
\begin{aligned}
& g_{1}(\|x\|) \leq V(t, x(t)) \leq g_{2}(\|x\|), \\
& { }_{0}^{C} D_{t}^{\beta} V(t, x(t)) \leq-g_{3}(\|x\|),
\end{aligned}
$$

where $0<\beta<1$, then the equilibrium point of system (3) is Mittag-Leffler stable.

Lemma 2. [20] If the fractional-order nonlinear system (3) is Mittag-Leffler stable, then it will be asymptotically stable, i.e., $\lim _{t \rightarrow \infty} x(t)=0$.

Lemma 3. [4, 16, 21] Let $x(t) \in \mathcal{R}^{n}$ be a continuous and derivable function. Then for any $t>0$,

$$
\frac{1}{2}_{0}^{C} D_{t}^{\alpha} x^{T}(t) x(t) \leq x^{T}(t)_{0}^{C} D_{t}^{\alpha} x(t) .
$$

As it is known, the exponential function, $e^{z}$, is a very important function in the stability analysis of integer-order systems. Its one-parameter generalization function is defined by [31]

$$
E_{\alpha}(z)=\sum_{k=0}^{\infty} \frac{z^{k}}{\Gamma(\alpha k+1)} .
$$

The two-parameter function of Mittag-Leffler type, which plays a very important role in the fractional calculus, was introduced by Agarwal [2]. The Mittag-Leffler function with two parameters can be written as

$$
E_{\alpha, \beta}(z)=\sum_{k=0}^{\infty} \frac{z^{k}}{\Gamma(\alpha k+\beta)},
$$

where $\alpha, \beta>0$ and $z \in C$. The Mittag-leffler function depends on the two parameters $\alpha$ and $\beta$. It is a spe- 
cial function and a complex function. If both $\alpha$ and $\beta$ are real and positive, the series converges for all values of the argument $z$, so the Mittag-Leffler function is an entire function. The Laplace transform of Mittag-Leffler function is [37]

$$
\mathscr{L}\left\{t^{\beta-1} E_{\alpha, \beta}\left(-a t^{\alpha}\right)\right\}=\frac{s^{\alpha-\beta}}{s^{\alpha}+a} .
$$

Lemma 4. [37] If $x(t) \in C^{1}[0, T]$ for some $T>0$, and $0<\alpha \leq 1$, then the following equations hold:

$$
{ }_{0}^{C} D_{t}^{-\alpha C} D_{t}^{\alpha} x(t)=x(t)-x(0)
$$

and

$$
{ }_{0}^{C} D_{t 0}^{\alpha C} D_{t}^{-\alpha} x(t)=x(t) .
$$

In this paper, we employ the Caputo version and use an algorithm for fractional order differential equations, which is the generalization of Adams-Bashforth-Moulton one. A brief introduction of the algorithm is given as follows.

Let consider the following fractional order differential equation:

$$
\left\{\begin{array}{l}
{ }_{0}^{C} D_{t}^{\alpha} y(t)=f(t, y(t)) \\
y(0)=y_{0}
\end{array}\right.
$$

According to Lemma 4, the above equation (11) is equivalent to the Volterra integral equation

$$
y(t)=y_{0}+\frac{1}{\Gamma(\alpha)} \int_{0}^{t}(t-\tau)^{\alpha-1} f(\tau, y(\tau)) d \tau .
$$

Let $h=T / N, N \in Z, t_{n}=n h, n=0,1, \cdots, N$. Then (12) can be approximated as [37]

$$
\begin{aligned}
y_{h}\left(t_{n+1}\right)= & y_{0}+\frac{h^{\alpha}}{\Gamma(\alpha+2)} f\left(t_{n}+1, y_{h}^{p}\left(t_{n+1}\right)\right) \\
& +\frac{h^{\alpha}}{\Gamma(\alpha+2)} \sum_{j=0}^{n} a_{j, n+1} f\left(t_{j}, y_{h}\left(t_{j}\right)\right)
\end{aligned}
$$

where $\quad a_{j, n+1}=n^{\alpha+1}-(n-\alpha)(n+1)^{\alpha} \quad$ for $\quad j=0$ and $a_{j, n+1}=(n-j+2)^{\alpha+1}+(n-j)^{\alpha+1}-2(n-j+1)^{\alpha+1} \quad$ for $\quad 1 \leq j \leq n$, $y_{0}+\frac{1}{\Gamma(\alpha)} \sum_{j=0}^{n} b_{j, n+1} f\left(t_{j}, y_{h}\left(t_{j}\right)\right), \quad p=\alpha+1, \quad$ and $b_{j, n+1}=\frac{h^{\alpha}}{\alpha}\left((n+1-j)^{\alpha}-(n-j)^{\alpha}\right)$.
The estimation error is $\max \left|y\left(t_{j}\right)-y_{h}\left(t_{j}\right)\right|=o\left(h^{p}\right)$ [37].

\section{Description of fractional-order financial chaotic systems}

The fractional-order financial chaotic system model to be used in this paper can be seen in $[10,13,32,46$, 47]. This mathematical model describes a fractional-order financial system by three nonlinear fractional-order differential equations. The model can be expressed as

$$
\left\{\begin{array}{l}
{ }_{0}^{C} D_{t}^{\alpha} x_{1}(t)=x_{3}(t)+\left(x_{2}(t)-a\right) x_{1}(t) \\
{ }_{0}^{C} D_{t}^{\alpha} x_{2}(t)=1-b x_{2}(t)-x_{1}^{2}(t) \\
{ }_{0}^{C} D_{t}^{\alpha} x_{3}(t)=-x_{1}(t)-c x_{3}(t),
\end{array}\right.
$$

where $a$ represents the saving amount, $b$ denotes the cost per investment, $c$ corresponds to the elasticity of demand of commercial market, and $0<\alpha<1$ is the fractional-order derivative. The first state variable $x_{1}(t)$, which represents the interest rate, can be affected by the surplus between investment and savings as well as structural adjustments of the prices. The second state variable $x_{2}(t)$ corresponds to the rate of investment, and inversely proportional to the cost of investment and the interest rate. The third state variable $x_{3}(t)$ depends on the difference between supply and demand in the market, and it can also be affected by the inflation rate.

It is easy to know that system (14) has three equilibrium points:

$$
\begin{aligned}
& E_{1}=\left(0, \frac{1}{b}, 0\right), \\
& E_{2}=\left(\sqrt{\frac{c-b-a b c}{c}}, \frac{1+a c}{c},-\frac{1}{c} \sqrt{\frac{c-b-a b c}{c}}\right), \\
& E_{3}=\left(-\sqrt{\frac{c-b-a b c}{c}}, \frac{1+a c}{c}, \frac{1}{c} \sqrt{\frac{c-b-a b c}{c}}\right) .
\end{aligned}
$$

The Jacobian matrix, at the equilibrium $E^{*}=\left[x_{1}^{*}, x_{2}^{*}, x_{3}^{*}\right]^{T}$, can be given as

$$
J_{E}=\left[\begin{array}{ccc}
-a+x_{2}^{*} & x_{1}^{*} & 1 \\
-2 x_{1}^{*} & -b & 0 \\
-1 & 0 & -c
\end{array}\right]
$$

Let $a=1, b=0.1$ and $c=1$. The eigenvalues for the fractional-order financial chaotic system equilibrium $E_{1}=(0.000 ; 10.000 ; 0.000)$ are $\lambda_{1}=8.8990$, 
$\lambda_{2}=-0.8990, \lambda_{3}=-0.1000$. Clearly, it is a saddle point. For equilibrium points $E_{2}=(0.8944 ; 2.000 ;-0.8944)$ and $E_{3}=(-0.8944 ; 2.000 ; 0.8944)$ they are: $\lambda_{1}=-0.7609$ and $\lambda_{2,3}=0.3304 \pm 1.4112 i$. It is a saddle-focus point. Since it is an unstable equilibrium, the condition for chaos is satisfied We can easily find that the minimal commensurate order of the system is $\alpha>0.8537$. Set the initial conditions be $x_{1}(0)=1, x_{2}(0)=2, x_{3}(0)=-0.5$, and the fractional order be $\alpha=0.91$. The chaotic attractor of the fractional-order financial system (14) is shown in Figures 1 and 2 when $\alpha=0.85$ and $\alpha=0.97$, respectively.

\section{Figure 1}

Chaotic behavior of fractional-order financial system (14) with $\alpha=0.85$ in (a) $x_{1}(t)-x_{2}(t)-x_{3}(t)$ plane, (b) $x_{1}(t)-x_{2}(t)$ plane, (c) $x_{1}(t)-x_{3}(t)$ plane and (d) $x_{1}(t)-x_{4}(t)$ plane

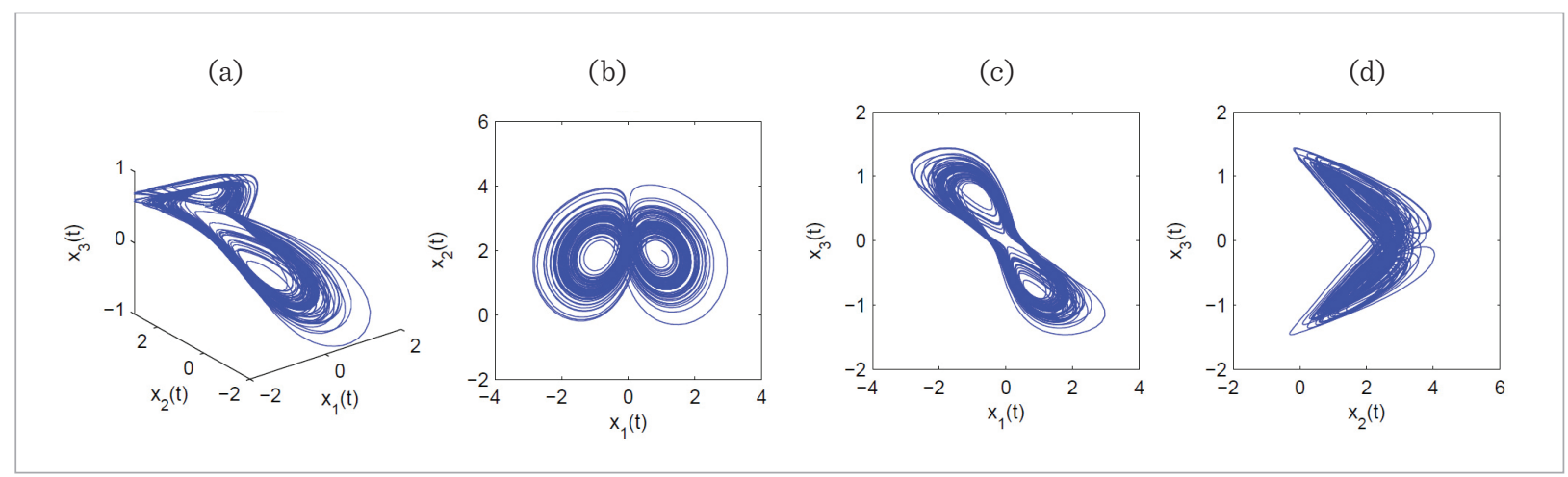

\section{Figure 2}

Chaotic behavior of fractional-order financial system (14) with $\alpha=0.97$ in (a) $x_{1}(t)-x_{2}(t)-x_{3}(t)$ plane, (b) $x_{1}(t)-x_{2}(t)$ plane, (c) $x_{1}(t)-x_{3}(t)$ plane and (d) $x_{1}(t)-x_{4}(t)$ plane

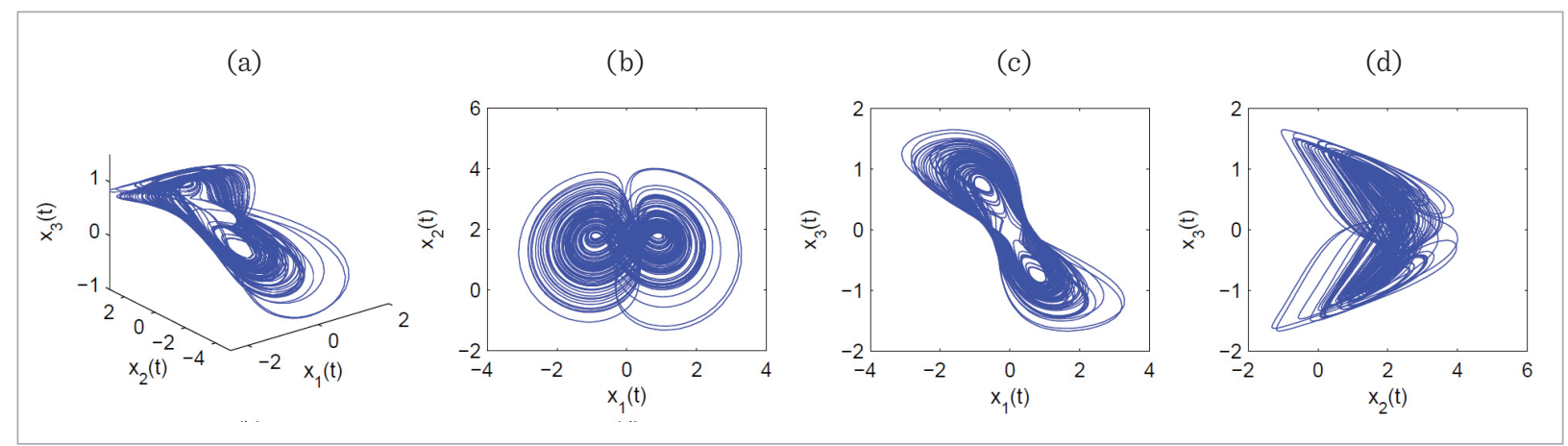

\section{Controller Design and Stability Analysis}

According to (14), the controlled model can be expressed as

$$
\left\{\begin{array}{l}
{ }_{0}^{C} D_{t}^{\alpha} x_{1}(t)=x_{3}(t)+\left(x_{2}(t)-a\right) x_{1}(t)+\Delta f_{1}(x(t))+d_{1}(t)+u_{1}(t), \\
{ }_{0}^{C} D_{t}^{\alpha} x_{2}(t)=1-b x_{2}(t)-x_{1}^{2}(t)+\Delta f_{2}(x(t))+d_{2}(t)+u_{2}(t), \\
{ }_{0}^{C} D_{t}^{\alpha} x_{3}(t)=-x_{1}(t)-c x_{3}(t)+\Delta f_{3}(x(t))+d_{3}(t)+u_{3}(t),
\end{array}\right.
$$


where $\Delta f_{i}(x(t))$ and $d_{i}(t), i=1,2,3$ are system uncertainties and unknown external disturbances, respectively, and $u_{i}(t)$ is the control input. Denote $f_{1}(x(t))=x_{3}(t)+\left(x_{2}(t)-a\right) x_{1}(t), \quad f_{2}(x(t))=1-b x_{2}(t)-x_{1}^{2}(t)$ and $f_{3}(x(t))=-x_{1}(t)-c x_{3}(t)$, then system (17) can be rewritten as

$$
{ }_{0}^{C} D_{t}^{\alpha} x_{i}(t)=f_{i}(x(t))+\Delta f_{i}(x(t))+d_{i}(t)+u_{i}(t), i=1,2,3 .
$$

Let the error state be

$$
e_{i}(t)=x_{i}(t)-x_{i}^{*}
$$

The control objective is to design the control input $u_{i}(t)$ so that the error variable $e_{i}(t)$ tends to the origin asymptotically with all signals in the closed-loop system remain bounded. To fulfil this assignment, the following assumptions are needed.

Assumption 1. The system uncertainty $\Delta f_{i}(x(t))$ is Lipschitz continuous, and there exist an unknown positive constant $\gamma_{i}$ such that

$$
\left|\Delta f_{i}(x(t))\right| \leq \gamma_{i}\|x(t)\|,
$$

where $\|\cdot\|$ denotes the Euclid norm.

Assumption 2. The external disturbance $d_{i}(t)$ is a bounded continuous function, i.e., $d_{i}(t)$ satisfies the following inequality

$$
\left|d_{i}(t)\right| \leq \bar{d}_{i},
$$

where $d_{i}$ is an unknown positive constant.

Remark 1. Assumptions 1 and 2 are not restrictive, and they are also used in many literatures, such as [22, 27, 28, 47], and so on. It should be pointed out that in this paper we assume that the exact values of $\bar{d}_{i}$ and $\gamma_{i}$ are unknown. In fact, these two assumptions enable us to have a simpler analysis of the system stability.

Note that the Caputo derivative of a constant is zero, from (18) and (19) we have

$$
{ }_{0}^{C} D_{t}^{\alpha} e_{i}(t)=f_{i}(x(t))+\Delta f_{i}(x(t))+d_{i}(t)+u_{i}(t) .
$$

Multiplying $e_{i}(t)$ to both sides of (22), and using Assumptions 1 and 2 , we have

$$
\begin{aligned}
e_{i}(t)_{0}^{C} D_{t}^{\alpha} e_{i}(t) & =e_{i}(t) f_{i}(x(t))+e_{i}(t) \Delta f_{i}(x(t))+e_{i}(t) d_{i}(t)+e_{i}(t) u_{i}(t), \\
& \leq e_{i}(t) f_{i}(x(t))+e_{i}(t) u_{i}(t)+\gamma_{i}\|x(t)\|\left|e_{i}(t)\right|+\bar{d}_{i}\left|e_{i}(t)\right| .
\end{aligned}
$$

Let us design the controller $u_{i}(t)$ as

$$
u_{i}(t)=-f_{i}(x(t))+\operatorname{sign}\left(e_{i}(t)\right) u_{r i}(t),
$$

where $u_{r i}(t)$ is a robust controller term which will be constructed later. Substituting (24) into (23) yields

$$
e_{i}(t)_{0}^{C} D_{t}^{\alpha} e_{i}(t) \leq\left|e_{i}(t)\right|\left(u_{r i}(t)+\gamma_{i}\|x(t)\|+\bar{d}_{i}\right) .
$$

Note that both $\gamma_{i}$ and $\bar{d}_{i}$ are unknown. So their values should be estimated in the controller design. Let $\hat{\gamma}_{i}(t)$ and $\hat{\bar{d}}_{i}(t)$ be the estimation of $\gamma_{i}$ and $\bar{d}_{i}$, respectively. Then, the robust term $u_{r i}(t)$ can be defined as

$$
u_{r i}(t)=-k_{i}\left|e_{i}(t)\right|-\hat{\gamma}_{i}(t)\|x(t)\|-\bar{d}_{i}(t) .
$$

where $k_{i}$ is positive design parameter. Substituting (26) into (25), we have

$e_{i}(t)_{0}^{C} D_{t}^{\alpha} e_{i}(t) \leq-k_{i}\left|e_{i}(t)\right|^{2}-\left|e_{i}(t)\right| \tilde{\gamma}_{i}(t)\|x(t)\|-\left|e_{i}(t)\right| \tilde{\bar{d}}_{i}$,

where

$$
\tilde{\gamma}_{i}(t)=\hat{\gamma}_{i}(t)-\gamma_{i}
$$

and

$$
\tilde{\bar{d}}_{i}(t)=\hat{\bar{d}}_{i}(t)-\bar{d}_{i}
$$

are the estimation errors of unknown parameters $\gamma_{i}$ and $\bar{d}_{i}$, respectively.

To proceed, let us give the following results on fractional calculus at first.

Lemma 5. If ${ }_{0}^{C} D_{t}^{\alpha} y(t) \leq 0$, then we have $y(t) \leq y(0)$ for all $t>0$, and furthermore, the function $y(t)$ is monotone decreasing.

Proof. There exists some nonnegative function $h(t)$ such that

$$
{ }_{0}^{C} D_{t}^{\alpha} y(t)+h(t)=0 \text {. }
$$


Using the Laplace transform to (30) we have

$$
Y(s)=\frac{y(0)}{s}-\frac{H(s)}{s^{\alpha}}
$$

where $Y(s)$ and $H(s)$ are the Laplace transform of $y(t)$ and $h(t)$, respectively.

Taking the inverse Laplace transform on (31) yields

$$
y(t)=y(0)-_{0}^{C} D_{t}^{-\alpha} h(t)
$$

Noting that $h(t) \geq 0$, it follows from (1) that ${ }_{0}^{C} D_{t}^{-\alpha} h(t) \geq 0$. As a result we know that $y(t) \leq y(0)$ for all $t>0$, and the function $y(t)$ is monotone decreasing.

Lemma 6. Let $V_{1}(t)=\frac{1}{2} x^{2}(t)+\frac{1}{2} y^{2}(t)$, where $x(t), y(t) \in \mathcal{R}$ are continuous functions. If

$$
{ }_{0}^{C} D_{t}^{\alpha} V_{1}(t) \leq-k x^{2}(t)
$$

where $k$ is a positive constant, then we have

$$
x^{2}(t) \leq 2 V_{1}(0) E_{\alpha}\left(-2 k t^{\alpha}\right) .
$$

Proof. Using the fractional integral operator ${ }_{0}^{C} D_{t}^{-\alpha}$ to both sides of (33), it follows from Lemma 4 that

$$
V_{1}(t)-V_{1}(0) \leq-k_{0}^{C} D_{t}^{-\alpha} x^{2}(t)
$$

It follows from (35) that

$$
x^{2}(t) \leq 2 V_{1}(0)-2 k_{0}^{C} D_{t}^{-\alpha} x^{2}(t) .
$$

There exists a nonnegative function $m(t)$ such that

$$
x^{2}(t)+m(t)=2 V_{1}(0)-2 k_{0}^{C} D_{t}^{-\alpha} x^{2}(t) .
$$

Taking the Laplace transform $(\mathscr{L}\{\cdot\})$ on (37) gives

$$
X_{2}(s)=2 V_{1}(0) \frac{s^{\alpha-1}}{s^{\alpha}+2 k}-2 \frac{s^{\alpha}}{s^{\alpha}+2 k} M(s)
$$

where $X_{2}(s)$ and $M(s)$ are Laplace transform of $x^{2}(t)$ and $m(t)$, respectively. Using (8), the solution of (38) can be given as

$$
x^{2}(t)=2 V_{1}(0) E_{\alpha}\left(-2 k t^{\alpha}\right)-2 m(t) *\left[t^{-1} E_{\alpha, 0}\left(-2 k t^{\alpha}\right)\right]
$$

where * represents the convolution operator. Noting that both $E_{\alpha, 0}\left(-2 k t^{\alpha}\right)$ and $t^{-1}$ are nonnegative functions, it follows from (39) that (34) holds. This ends the proof of Lemma 6.

Based on above discussions, now we are ready to give the following results.

Theorem 1. Consider the fractional-order financial chaotic system (17) or the equivalent form (18). Suppose that Assumptions 1 and 2 are satisfied Let the control input be (24) and (26). If $\hat{\gamma}_{i}(t)$ and $\bar{d}_{i}(t)$ are updated by the following fractional-order differential equations

$$
{ }_{0}^{C} D_{t}^{\alpha} \hat{\gamma}_{i}(t)=h_{i}\left|e_{i}(t)\right|\|x(t)\|
$$

and

$$
{ }_{0}^{C} D_{t}^{\alpha} \hat{\bar{d}}_{i}(t)=m_{i}\left|e_{i}(t)\right|
$$

respectively, where $h_{i}$ and $m_{i}$ are positive design parameters, then the system variable $x_{i}(t)$ will tend to the origin asymptotically, and all signals in the closedloop system will keep bounded.

Proof. Let us consider the following Lyapunov function candidate:

$$
V_{i}(t)=\frac{1}{2} e_{i}^{2}(t)+\frac{1}{2 h_{i}} \tilde{\gamma}_{i}^{2}(t)+\frac{1}{2 m_{i}} \tilde{\bar{d}}_{i}^{2}(t) .
$$

Then by using Lemma 3, we have

${ }_{0}^{C} D_{t}^{\alpha} V_{i}(t) \leq e_{i}(t)_{0}^{C} D_{t}^{\alpha} e_{i}(t)+\frac{1}{h_{i}} \tilde{\gamma}_{i}(t)_{0}^{C} D_{t}^{\alpha} \tilde{\gamma}_{i}(t)+\frac{1}{m_{i}} \tilde{\bar{d}}_{i}(t)_{0}^{C} D_{t}^{\alpha} \tilde{\bar{d}}_{i}(t)$.

Noting that the fractional-order derivative of a constant is zero, from (28) and (29) we have

$$
{ }_{0}^{C} D_{t}^{\alpha} \tilde{\gamma}_{i}(t)={ }_{0}^{C} D_{t}^{\alpha} \hat{\gamma}_{i}(t)
$$

and

$$
{ }_{0}^{C} D_{t}^{\alpha} \tilde{\bar{d}}_{i}(t)={ }_{0}^{C} D_{t}^{\alpha} \hat{\bar{d}}_{i}(t) .
$$

Substituting (27), (44) and (45) into (43), we have

$$
\begin{aligned}
{ }_{0}^{C} D_{t}^{\alpha} V_{i}(t) \leq & -k_{i}\left|e_{i}(t)\right|^{2}-\left|e_{i}(t)\right| \tilde{\gamma}_{i}(t)\|x(t)\|-\left|e_{i}(t)\right| \tilde{\bar{d}}_{i} \\
& +\frac{1}{h_{i}} \tilde{\gamma}_{i}(t)_{0}^{C} D_{t}^{\alpha} \hat{\gamma}_{i}(t)+\frac{1}{m_{i}} \tilde{\bar{d}}_{i}(t){ }_{0}^{C} D_{t}^{\alpha} \hat{\bar{d}}_{i}(t) .
\end{aligned}
$$


Then substituting (40) and (41) into (46) gives

$$
{ }_{0}^{C} D_{t}^{\alpha} V_{i}(t) \leq-k_{i}\left|x_{i}(t)\right|^{2} .
$$

Thus we have ${ }_{0}^{C} D_{t}^{\alpha} V_{i}(t) \leq 0$. According to Lemma 5 , we know that all signals in the closed-loop system will keep bounded. From Lemma 6 and (47), we can conclude that $e_{i}(t)$ will converge to the origin asymptotically. This ends the proof of Theorem 1.

Remark 2. In the stability analysis of fractional order nonlinear systems, the Lyapunov function candidate $V(t)=2 e^{T}(t) e(t)$ is often used. The $\alpha$ th-order of $V(t)$ can be given as

$$
{ }_{0}^{C} D_{t}^{\alpha} V(t)=\left({ }_{0}^{C} D_{t}^{\alpha} e(t)\right)^{T} e(t)+e^{T}(t){ }_{0}^{C} D_{t}^{\alpha} e(t)+2 \Lambda
$$

where

$$
\Lambda=\sum_{i=1}^{\infty} \frac{\Gamma(1+\alpha)}{\Gamma(1+i) \Gamma(1-i+\alpha)}{ }_{0}^{C} D_{t}^{i} e(t)_{0}^{C} D_{t}^{\alpha-i} e(t) .
$$

We can see that it is very hard to use the above complicated infinite series to analyze the stability of fractional order systems. However, in this paper, by using Lemma 3 and the proposed Lemma 6, we need not to tackle the above complicated infinite series.

Remark 3. To update $\hat{\gamma}_{i}(t)$ and $\hat{\bar{d}}_{i}(t)$, fractional-order adaptation laws (40) and (41) are designed. Compared with classical integer-order adaptation law, the fractional-order adaptation laws enlarge the parameter adaptation performance by heightening one degree of freedom.

Remark 4. It is worth to mention that sliding mode control methods are often used to control fractional-order nonlinear systems, for example, in [3, 5, 9, 17] and many others. How to control fractional-order financial chaotic system by using sliding mode control method is one of our research directions.

\section{Simulation Studies}

In the simulation, the system uncertainties are chosen as:

$$
\begin{array}{ll}
\Delta f_{1}(x(t)) & =0.3 \sin \left(x_{1}(t)\right)+0.1 x_{2}(t)-\sin \left(x_{3}(t)\right), \\
\Delta f_{2}(x(t)) & =0.1 x_{1}(t)+0.2 \sin \left(x_{2}(t)\right)+\sin \left(x_{3}(t)\right), \\
\Delta f_{3}(x(t)) & =0.1 x_{1}(t)-0.2 x_{2}(t)+\sin \left(x_{3}(t)\right),
\end{array}
$$

from which we can easily conclude that Assumption 1 is satisfied. Let the external disturbances be $d_{1}(t)=0.2 \sin (t), d_{2}(t)=0.1 \cos (t), d_{3}(t)=0.1 \sin (t)+0.1 \cos (t)$. The controller design parameters are chosen as $k_{1}=k_{2}=k_{3}=1, h_{1}=h_{2}=h 3=0.3, m_{1}=m_{2}=m_{3}=0.2$. The initial conditions of the fractional order adaptation law are chosen as $\hat{\gamma}_{1}(0)=0.2, \hat{\gamma}_{2}=0.5, \hat{\gamma}_{3}=2$, $\hat{\bar{d}}_{1}(0)=0.2, \hat{\bar{d}}_{2}(0)=0.5, \hat{\bar{d}}_{3}(0)=0.7$. To eliminate the chattering phenomenon, the discontinuous term $\operatorname{sign}(\cdot)$ is replaced by $\arctan (10 \cdot)$.

Let $\alpha=0.91$. First, let us consider the condition that controlling the fractional-order financial system (17) to the equilibrium point $E_{1}=\left(0, \frac{1}{b}, 0\right)$. The simulation results are presented in Figures 3-7. Time responses of system variables $x_{1}(t), x_{2}(t)$ and $x_{3}(t)$ are depicted in Figure 3. Time responses of the control

\section{Figure 3}

Controlling the fractional-order financial chaotic system (17) to its equilibrium point $E_{1}=\left(0, \frac{1}{b}, 0\right)$ : time responses of the state variables. The controller is activated at $t=30$

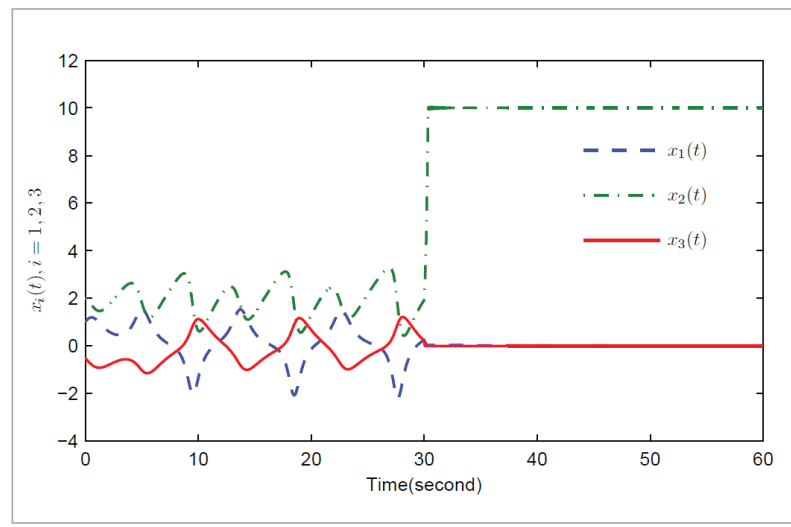

inputs are included in Figure 5. The estimations of the unknown parameters $\hat{\gamma}_{i}(t)$ and $\hat{\bar{d}}_{i}(t)$ are depicted in Figures 6 and 7 , respectively. From the simulation results, we can see that the good control performance has been obtained, and the system variables converge to the origin rapidly when the controller is activated at $t=30$. 
Figure 4

Controlling the fractional-order financial chaotic system (17) to its equilibrium point $E_{1}=\left(0, \frac{1}{b}, 0\right)$ : time responses of the tracking errors $e_{i}(t)$. The controller is activated at $t=30$

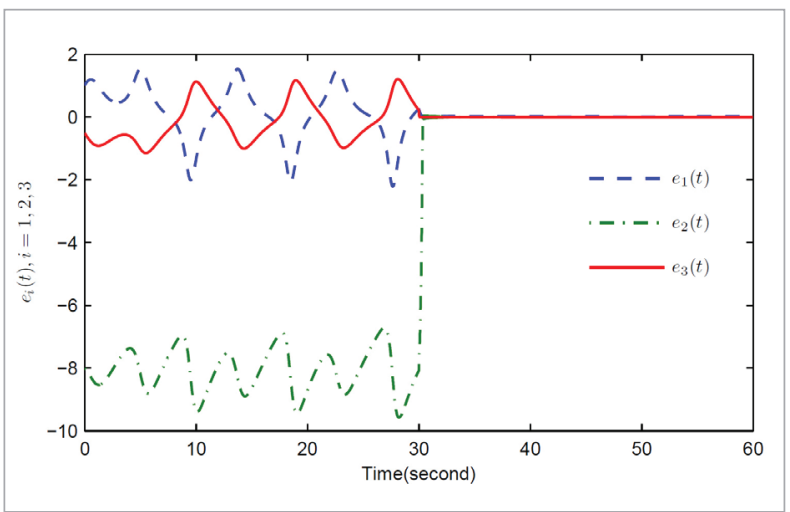

\section{Figure 5}

Controlling the fractional-order financial chaotic system (17) to its equilibrium point $E_{1}=\left(0, \frac{1}{b}, 0\right)$ : time responses of the control inputs. The controller is activated at $t=30$

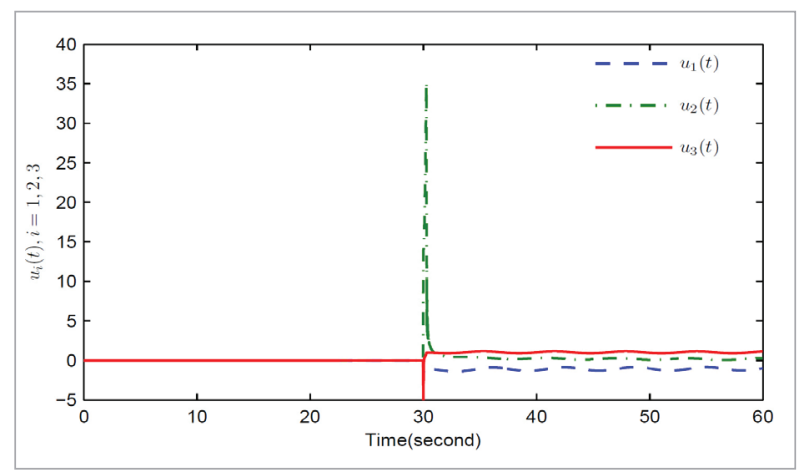

\section{Figure 6}

Controlling the fractional-order financial chaotic system (17) to its equilibrium point $E_{1}=\left(0, \frac{1}{b}, 0\right)$ : time responses of $\hat{\gamma}_{i}(t)$. The controller is activated at $t=30$

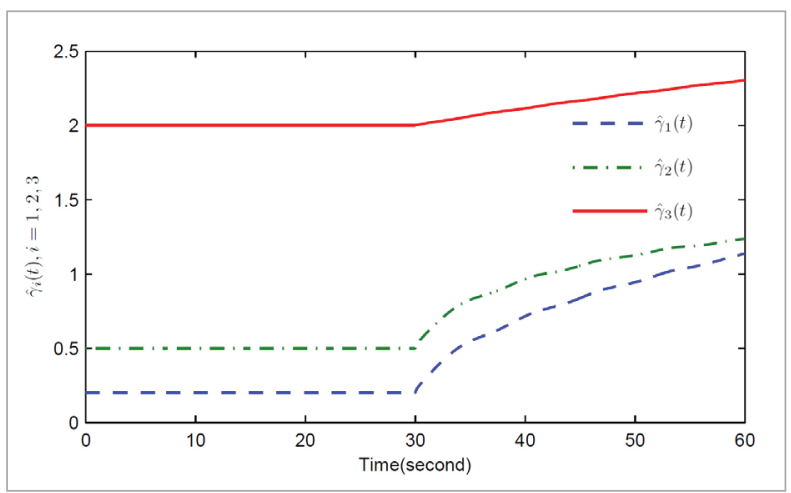

Figure 7

Controlling the fractional-order financial chaotic system (17) to its equilibrium point $E_{1}=\left(0, \frac{1}{b}, 0\right)$ : time responses of $\hat{\bar{d}}_{i}(t)$. The controller is activated at $t=30$

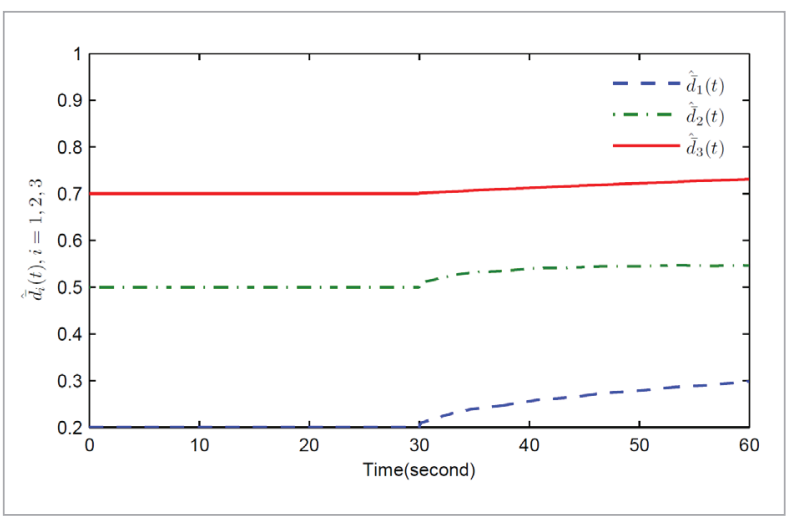

\section{Figure 8}

Controlling the fractional-order financial chaotic system (17) to its equilibrium point $E_{2}=\left(\sqrt{\frac{c-b-a b c}{c}}, \frac{1+a c}{c},-\frac{1}{c} \sqrt{\frac{c-b-a b c}{c}}\right)$.

The controller is activated at $t=30$

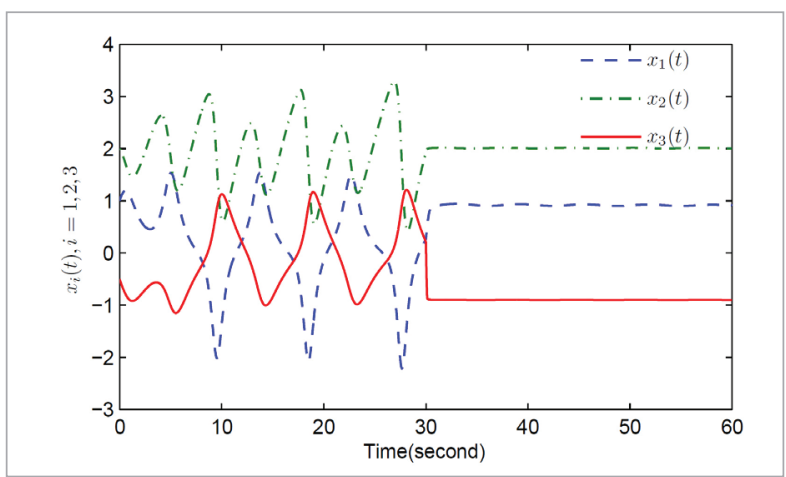

\section{Figure 9}

Controlling the fractional-order financial chaotic system (17) to its equilibrium point $E_{3}=\left(-\sqrt{\frac{c-b-a b c}{c}}, \frac{1+a c}{c}, \frac{1}{c} \sqrt{\frac{c-b-a b c}{c}}\right)$. The controller is activated at $t=30$

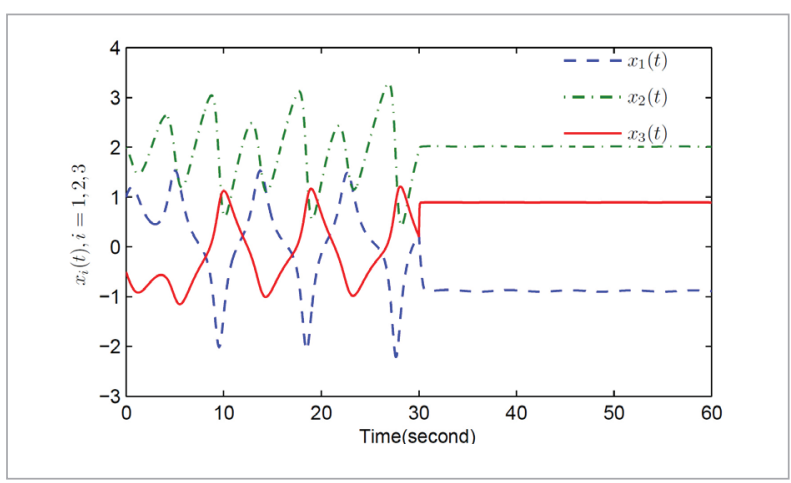


Then, the simulation results of controlling the fractional-order financial chaotic system (17) to its equilibrium points

$E_{2}=\left(\sqrt{\frac{c-b-a b c}{c}}, \frac{1+a c}{c},-\frac{1}{c} \sqrt{\frac{c-b-a b c}{c}}\right)$

and $E_{3}=\left(-\sqrt{\frac{c-b-a b c}{c}}, \frac{1+a c}{c}, \frac{1}{c} \sqrt{\frac{c-b-a b c}{c}}\right)$

are presented in Figures 8 and 9, respectively.

It should be stressed that the proposed control method can be used to control a very large scale of fractional-order chaotic systems. Finally, to confirm the effectiveness of the proposed control method, let us consider controlling a novel fractional-order financial chaotic system which can be described by [40]

$\left\{\begin{array}{l}{ }_{0}^{C} D_{t}^{\alpha} x_{1}(t)=x_{3}(t)+\left(x_{2}(t)-a\right) x_{1}(t)+\Delta f_{1}(x(t))+d_{1}(t)+u_{1}(t), \\ { }_{0}^{C} D_{t}^{\alpha} x_{2}(t)=1-b x_{2}(t)-\left|x_{1}(t)\right|+\Delta f_{2}(x(t))+d_{2}(t)+u_{2}(t), \\ { }_{0}^{C} D_{t}^{\alpha} x_{3}(t)=-x_{1}(t)-c x_{3}(t)+\Delta f_{3}(x(t))+d_{3}(t)+u_{3}(t),\end{array}\right.$
When $\Delta f_{i}=d_{i}=u_{i}=0, \quad a=1, b=0.15, \quad c=1 \quad$ and $x(0)=(1.5,2,-1.5)$, system (51) shows chaotic behavior, which is depicted in Figure 10.

In the simulation, the system uncertainties are chosen as: $\Delta f_{1}(x(t))=0.3 \cos \left(x_{1}(t)\right)+0.1 x_{3}(t)$, $\Delta f_{2}(x(t))=0.1 x_{2}(t)+0.2 \sin \left(x_{2}(t)\right)$, and $\Delta f_{3}(x(t))=0.1 x_{1}(t)+$ $\sin \left(x_{3}(t)\right)$. Let the external disturbances be $d_{1}(t)=0.2 \sin (t), d_{2}(t)=0.1 \cos (t), \quad d_{3}(t)=0.1 \sin (t) . \quad$ The controller design parameters are chosen as $k_{1}=k_{2}=k_{3}=1, h_{1}=h_{2}=h 3=0.3, m_{1}=m_{2}=m_{3}=0.2$.

The initial conditions of the fractional-order adaptation laws are chosen as

$\hat{\gamma}_{1}(0)=0.1, \hat{\gamma}_{2}=0.2, \hat{\gamma}_{3}=0.3, \hat{\bar{d}}_{1}(0)=0.1$,

$\bar{d}_{2}(0)=0.2, \bar{d}_{3}(0)=0.3$.

The simulation results are presented in Figure 11, from which we can see that good control performance has also been obtained.

\section{Figure 10}

Chaotic behavior of fractional-order financial system (51) with $\alpha=0.97$ in (a) $x_{1}(t)-x_{2}(t)-x_{3}(t)$ plane, (b) $x_{1}(t)-x_{2}(t)$ plane, (c) $x_{1}(t)-x_{3}(t)$ plane and (d) $x_{1}(t)-x_{4}(t)$ plane

(a)

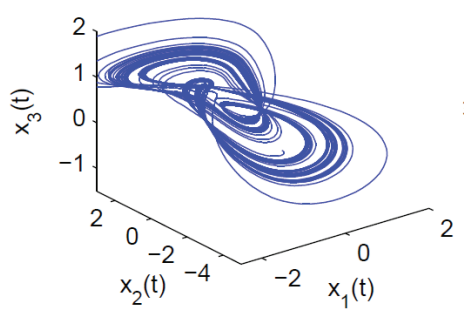

(c)

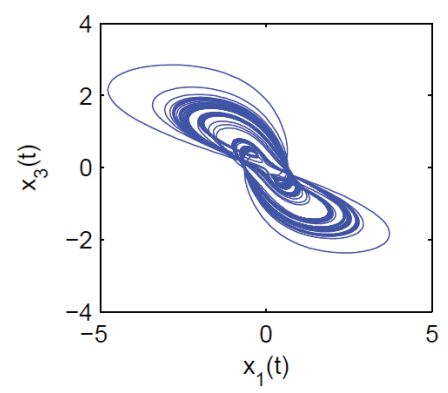

(b)

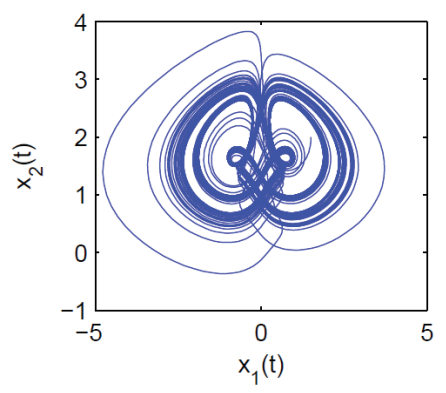

(d)

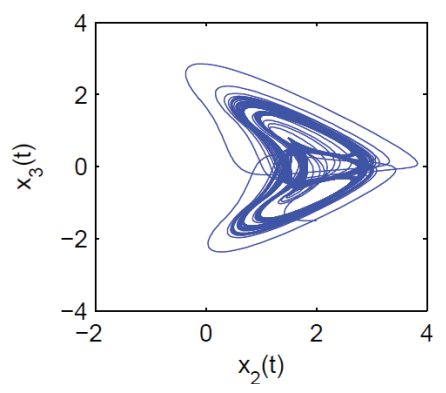




\section{Figure 11}

Controlling the fractional-order financial chaotic system (51) to its equilibrium point $E_{1}=\left(-\frac{c-b-a b c}{c}, \frac{1+a c}{c}, \frac{c-b-a b c}{c^{2}}\right)$
in $\left(\right.$ a) $x_{i}(t),(\mathrm{b}) u_{i}(t),(\mathrm{c}) \hat{\gamma}_{i}(t)$ and (d) $\hat{\bar{d}}_{i}(t)$. The controller is activated at $t=30$

(a)

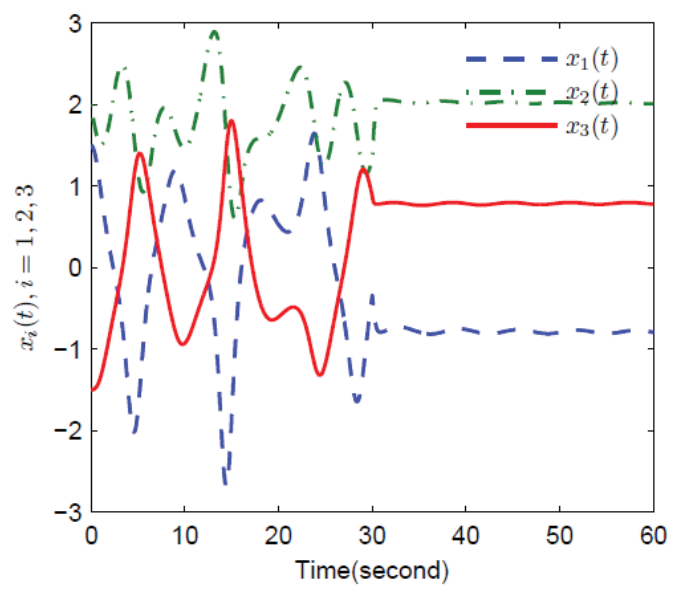

(c)

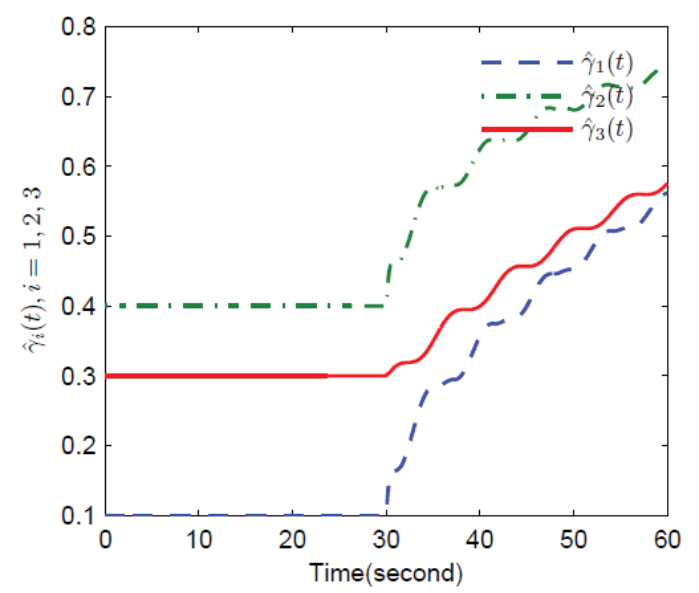

(b)

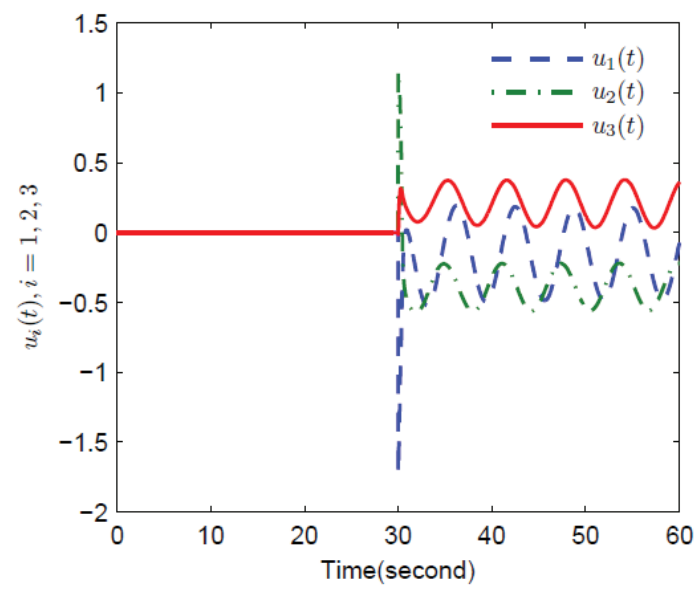

(d)

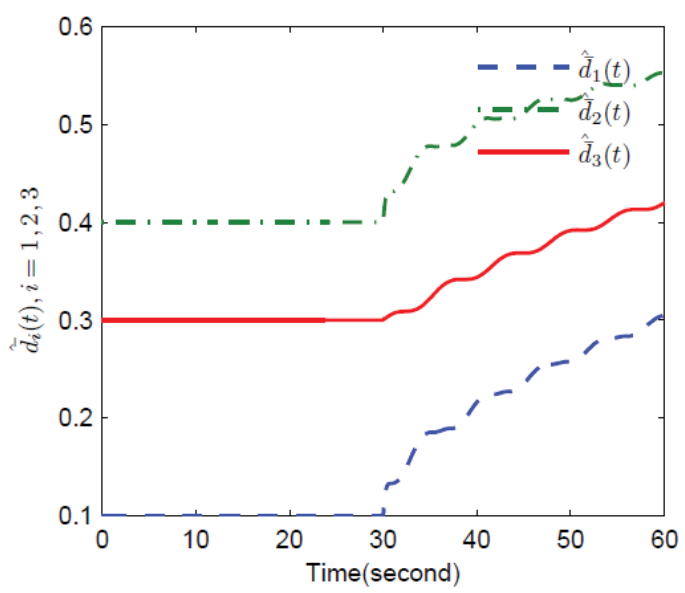

\section{Conclusions}

The economic systems contain many complex factors which are important to governments. So controlling the fractional-order chaotic financial systems by using effective control method is an interesting yet challenging work. This paper mainly discusses this problem by means of adaptive control. The following three aspects are included: (1) the stability analysis for fractional-order financial chaotic systems based on fractional-order Lyapunov second method; (2) fractional-order adaptation law and its application in the stability analysis for fractional-order nonlinear systems; (3) the usage of quadratic Lyapunov functions in stability analysis 
of fractional-order systems. The results of our results may enrich the control theorem of fractional-order systems, and the proposed control method can also be extended to other fractional-order systems.

\section{Acknowledgements}

The authors are indebted to the anonymous reviewers' valuable comments, which improved the presentation and quality of this paper. This work is supported

\section{References}

1. Abd-Elouahab, M. S., Hamri, N. E., Wang J. Chaos control of a fractional-order financial system. Mathematical Problems in Engineering, 2010, 270646. http://dx.doi. org/10.1155/2010/270646

2. Agarwal R. P. A propos d'une note de m. Pierre Humbert. Comptes Rendus de l'Académie des Sciences, 1953, 236(21), 2031-2032.

3. Aghababa, M. P. Design of hierarchical terminal sliding mode control scheme for fractional-order systems. IET Science, Measurement and Technology, 2015, 9(1), 122133. http://dx.doi.org/10.1049/iet-smt.2014.0039

4. Aguila-Camacho, N., Duarte-Mermoud, M. A., Gallegos, J. A. Lyapunov functions for fractional order systems. Communications in Nonlinear Science and Numerical Simulation, 2014, 19(9), 2951-2957. http://dx.doi. org/10.1016/j.cnsns.2014.01.022

5. Balasubramaniam, P., Muthukumar, P., Ratnavelu, K. Theoretical and practical applications of fuzzy fractional integral sliding mode control for fractional-order dynamical system. Nonlinear Dynamics, 2015, 80(1-2), 249-267. http://dx.doi.org/10.1007/s11071-014-1865-4

6. Benchohra, M., Henderson, J., Ntouyas, S. K., Ouahab, A. Existence results for fractional order functional differential equations with infinite delay. Journal of Mathematical Analysis and Applications, 2008, 338(2), 13401350. http://dx.doi.org/10.1016/j.jmaa.2007.06.021

7. Cao, J., Ho, D. W. C., Yang, Y. Projective synchronization of a class of delayed chaotic systems via impulsive control. Physics Letters A, 2009, 373(35), 3128-3133. http:// dx.doi.org/10.1016/j.physleta.2009.06.056

8. Cao, J., Li, L. Cluster synchronization in an array of hybrid coupled neural networks with delay. Neural Networks, 2009, 22(4), 335-342. http://dx.doi.org/10.1016/j. neunet.2009.03.006

9. Chen, D., Liu, Y., Ma, X., Zhang, R. Control of a class of fractional-order chaotic systems via sliding mode. Non- by the National Natural Science Foundation of China (Grant No. 61403157), the Natural Science Foundation for the Higher Education Institutions of Anhui Province of China (Grant Nos. KJ2015A256, KJ2016A665 and KJ2016A666), the Foundation for Distinguished Young Talents in Higher Education of Anhui Province of China (Grant No. GXYQZD2016257), and the Innovation Funds of Graduate Programs of Shaanxi Normal University (Grant No. 2015CXB008).

linear Dynamics, 2012, 67(1), 893-901. http://dx.doi. org/10.1007/s11071-011-0002-x

10. Chen, L., Chai, Y., Wu, R. Control and synchronization of fractional-order financial system based on linear control. Discrete Dynamics in Nature and Society, 2011, 958393. http://dx.doi.org/10.1155/2011/958393

11. Chen, L., Chai, Y., Wu, R., Ma, T., Zhai, H. Dynamic analysis of a class of fractional-order neural networks with delay. Neurocomputing, 2013, 111, 190-194. http://dx.doi. org/10.1016/j.neucom.2012.11.034

12. Chen, L., Wu, R., He, Y., Yin, L. Robust stability and stabilization of fractional-order linear systems with polytopic uncertainties. Applied Mathematics and Computation, 2015, 257, 274-284. http://dx.doi.org/10.1016/j. amc.2014.12.103

13. Chen, W. C. Nonlinear dynamics and chaos in a fractional-order financial system. Chaos, Solitons and Fractals, 2008, 36(5), 1305-1314. http://dx.doi.org/10.1016/j.chaos.2006.07.051

14. Dadras, S., Momeni, H. R. Control of a fractional-order economical system via sliding mode. Physica A: Statistical Mechanics and its Applications, 2010, 389(12), 24342442. http://dx.doi.org/10.1016/j.physa.2010.02.025

15. De-Cesare, L., Sportelli, M. A dynamic IS-LM model with delayed taxation revenues. Chaos, Solitons and Fractals, 2005, 25(1), 233-244. http://dx.doi.org/10.1016/j.chaos.2004.11.044

16. Duarte-Mermoud, M. A., Aguila-Camacho, N., Gallegos, J. A., Castro-Linares, R. Using general quadratic Lyapunov functions to prove Lyapunov uniform stability for fractional order systems. Communications in Nonlinear Science and Numerical Simulation, 2015, 22(1-3), 650-659. http://dx.doi.org/10.1016/j.cnsns.2014.10.008

17. Gao, L., Wang, Z., Zhou, K.,Zhu, W., Wu,Z., Ma, T.Modified sliding mode synchronization of typical three-dimensional fractional-order chaotic systems. Neurocomput- 
ing, 2015, 166, 53-58. http://dx.doi.org/10.1016/j.neucom.2015.04.031

18. Kocamaz, U. E., G“oksu, A., Ta skıı, H., Uyaro glu, Y. Synchronization of chaos in nonlinear finance system by means of sliding mode and passive control methods: A comparative study. Information Technology And Control, 2015, 44(2), 172-181. http://dx.doi.org/10.5755/j01. itc.44.2.77732

19. Li, C., Deng, W. Remarks on fractional derivatives. Applied Mathematics and Computation, 2007, 187(2), 777784. http://dx.doi.org/10.1016/j.amc.2006.08.163

20. Li, Y., Chen, Y. Q., Podlubny, I. Mittag-Leffler stability of fractional order nonlinear dynamic systems. Automatica, 2009, 45(8), 1965-1969. http://dx.doi.org/10.1016/j. automatica.2009.04.003

21. Liu, H., Li, S., Sun, Y., Wang, H. Adaptive fuzzy synchronization for uncertain fractional-order chaotic systems with unknown non- symmetrical control gain. Acta Physica Sinaca, 2015, 64(7), 070503. http://dx.doi. org/10.7498/aps.64.070503

22. Liu, H., Li, S., Sun, Y., Wang, H. Prescribed performance synchronization for fractional-order chaotic systems. Chinese Physics B, 2015, 24(9), 090505. http://dx.doi. org/10.1088/1674-1056/24/9/090505

23. Liu, H., Li, S., Cao, J., Li, G., Alsaedi, A., Alsaadi, F. E. Adaptive fuzzy prescribed performance controller design for a class of uncertain fractional- order nonlinear systems with external disturbances. Neurocomputing, 2017, 219, 422-430. http://dx.doi.org/10.1016/j.neucom.2016.09.050

24. Liu, H., Li, S., Wang, H., Huo, Y., Luo, J. Adaptive synchronization for a class of uncertain fractional-order neural networks. Entropy, 2015, 17(10), 7185-7200. http://dx. doi.org/10.3390/e17107185

25. Liu, H., Pan, Y., Li, S., Chen, Y. Adaptive fuzzy backstepping control of fractional-order nonlinear systems. IEEE Transactions on Systems, Man, and Cybernetics: Systems, 201\%. http://dx.doi.org/10.1109/ TSMC.2016.2640950

26. Lorenz, H. W., Nusse, H. E. Chaotic attractors, chaotic saddles, and fractal basin boundaries: Goodwin's nonlinear accelerator model reconsidered. Chaos, Solitons and Fractals, 2002, 13(5), 957-965. http://dx.doi.org/10.1016/ S0960-07r9(01)00121-7

27. Luo, J., Li, G., Liu, H. Linear control of fractional-order financial chaotic systems with input saturation. Discrete Dynamics in Nature and Society, 2014, 802429. http://dx.doi.org/10.1155/2014/802429

28. Luo, J., Liu, H., Yang, J. Robust synchronization of uncertain fractional order chaotic systems. IEICE Transac- tions on Fundamentals of Electronics, Communications and Computer Sciences, 2015, 98(10), 2109-2116. http:// dx.doi.org/10.1587/transfun.E98.A.2109

29. Mathiyalagan, K., Park, J. H., Sakthivel, R. Exponential synchronization for fractional-order chaotic systems with mixed uncertainties. Complexity, 2015, 21(1), 114125. http://dx.doi.org/10.1002/cplx.21547

30. Mesbahi,A.,Haeri, M. Robustnon-fragilefractional order PID controller for linear time invariant fractional delay systems. Journal of Process Control, 2014, 24(9), 14891494. http://dx.doi.org/10.1016/j.jprocont.2014.07.001

31. Mittag-Leffler, G. M. Sur la nouvelle fonction $\mathrm{e}_{\alpha}(\mathrm{x})$. Comptes Rendus de l'Académie des Sciences, 1903, 137, 554-558.

32. Pan, I., Das, S., Das, S. Multi-objective active control policy design for commensurate and incommensurate fractional order chaotic financial systems. Applied Mathematical Modelling, 2015, 39(2), 500-514. http://dx.doi. org/10.1016/j.apm.2014.06.005

33. Pan, Y., Er, M. J., Huang, D., Sun, T. Practical adaptive fuzzy $\mathrm{H} \infty$ tracking control of uncertain nonlinear systems. International Journal of Fuzzy Systems, 2012, 14(4), 463-473. http://dx.doi.org/2-s2.0-84874045401

34. Pan, Y., Er, M. J., Huang, D., Wang, Q. Adaptive fuzzy control with guaranteed convergence of optimal approximation error. IEEE Transactions on Fuzzy Systems, 2011, 19(5), 807-818. http://dx.doi.org/10.1109/ TFUZZ.2011.2144600

35. Pan, Y., Er, M. J., Huang, D., Wang, Q. Fire-Rule-Based direct adaptive type-2 fuzzy Ho tracking control. Engineering Applications of Artificial Intelligence, 2011, 24(7), 1174-1185. http://dx.doi.org/10.1016/j.engappai.2011.05.016

36. Pan, Y., Zhou, Y., Sun, T., Er, M. J. Composite adaptive fuzzy $\mathrm{H} \infty$ tracking control of uncertain nonlinear systems. Neurocomputing, 2013, 99, 15-24. http://dx.doi. org/10.1016/j.neucom.2012.05.011

37. Podlubny, I. Fractional differential equations: an introduction to fractional derivatives, fractional differential equations, to methods of their solution and some of their applications, volume 198. Academic press, 1998.

38. Sasakura, K. On the dynamic behavior of Schinasi's business cycle model. Journal of Macroeconomics, 2014, 16(3), 423-444. http://dx.doi.org/10.1016/01640704(94)90015-9

39. Shen, J., Lam, J. Non-existence of finite-time stable equilibria in fractional-order nonlinear systems. Automatica, 2014, 50(2), 547-551. http://dx.doi.org/10.1016/j.automatica.2013.11.018

40. Tacha, O. I., Volos, C. K., Kyprianidis, I. M., Stouboulos, I. N., Vaidyanathan,S.,Pham, V.T.Analysis, adaptivecontrol 
and circuit simulation of a novel nonlinear finance system. Applied Mathematics and Computation, 2016, 276, 200-217. http://dx.doi.org/10.1016/j.amc.2015.12.015

41. Tavazoei, M. S., Haeri, M. Chaotic attractors in incommensurate fractional order systems. Physica D: Nonlinear Phenomena, 2008, 237(20), 2628-2637. http://dx.doi. org/10.1016/j.physd.2008.03.037

42. Uyaroğlu, Y., Kocamaz, U. E., Goksu, A., Can, E. Sliding mode control of hyperchaotic finance system. In: 1st International Work-Conference on Time Series (ITISE), 2014, 260-268.

43. Wang, Z., Huang, X., Shi, G. Analysis of nonlinear dynamics and chaos in a fractional order financial system with time delay. Computers and Mathematics with Applications, 2011, 62(3), 1531-1539. http://dx.doi.org/10.1016/j. camwa.2011.04.057

44. Wen, G., Hu, G., Yu, W., Cao, J., Chen, G. Consensus tracking for higher- order multi-agent systems with switching directed topologies and occasion- ally missing control inputs. Systems and Control Letters, 2013, 62(12), 11511158. http://dx.doi.org/10.1016/j.sysconle.2013.09.009

45. Wu, R., Lu, Y., Chen, L. Finite-time stability of fractional delayed neural networks. Neurocomputing, 2015, 149, 700-707. http://dx.doi.org/10.1016/j.neucom.2014.07.060
46. Xin, B., Zhang, J. Finite-time stabilizing a fractional-order chaotic financial system with market confidence. Nonlinear Dynamics, 2015, 79(2), 1399-1409. http://dx. doi.org/10.1007/s11071-014-1749-7

47. Xu, Y., He, Z. Synchronization of variable-order fractional financial system via active control method. Open Physics, 2013, 11(6), 824-835. http://dx.doi.org/10.2478/ s11534-013-0237-x

48. Yu, H., Cai, G., Li, Y. Dynamic analysis and control of a new hyperchaotic finance system. Nonlinear Dynamics, 2012, 67(3), 2171-2182. http://dx.doi.org/10.1007/ s110r1-011-0137-9

49. Yu, J., Hu, C., Jiang, H., Fan, X. Projective synchronization for fractional neural networks. Neural Networks, 2014, 49, 87-95. http://dx.doi.org/10.1016/j.neunet.2013.10.002

50. Zhang, X., Liu, X., Zheng, Y., Liu, C. Chaotic dynamic behavior analysis and control for a financial risk system. Chinese Physics B, 2013, 22(3), 030509. http://dx.doi. org/10.1088/1674-1056/22/3/030509

51. Zhao, M., Wang, J. Ho control of a chaotic finance system in the presence of external disturbance and input time delay. Applied Mathematics and Computation, 2014, 233, 320-327. http://dx.doi.org/10.1016/j.amc.2013.12.085

\section{Summary / Santrauka}

In this paper, robust adaptive control for uncertain fractional-order financial chaotic systems with bounded unknown external disturbances is studied. By utilizing the fractional-order extension of the classical Lyapunov stability methods, an adaptive controller is presented for controlling the fractional-order financial chaotic system. Quadratic Lyapunov functions are employed in the stability analysis, and fractional-order adaptation laws are designed to update controller parameters online. The proposed controller can ensure that the system states converge to the origin asymptotically and all signals in the closed-loop system remain bounded. Finally, simulation results are presented to confirm our theoretical results.

Straipsnyje tiriamas stiprus adaptyvus nepastoviujų frakcinès eilès chaotiškujų sistemų su apribotais išoriniais trikdžiais valdymas. Panaudojant klasikinių Liapunovo stabilumo metodų frakcinès eilès papildinį, pristatomas adaptyvus valdiklis frakcinès eilès finansinei chaotiškajai sistemai valdyti. Stabilumo analizėje naudojamos kvadratinių Liapunovo lygčių funkcijos, o frakcinės eilès prisitaikymo dėsniai sukurti taip, kad juos taikant būtų atnaujinti valdiklio parametrai internete. Siūlomas valdiklis gali užtikrinti, kad sistemos būsenos konverguotų i kilmès šaltinį asimptomiškai ir visi signalai uždaro rato sistemoje išliktų apriboti. Autorių teoriniai rezultatai patvirtinami simuliacijos rezultatais. 